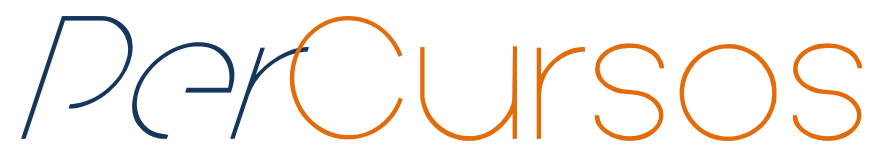

\title{
O lugar das interações entre os diferentes movimentos sociais na "definição" dos territórios de povos e comunidades tradicionais
}

\begin{abstract}
Resumo
Buscamos nesse artigo apontar algumas das ressignificações operadas na categoria "território" a partir da emergência e consolidação das demandas e lutas políticas dos povos e comunidades tradicionais. Se a literatura a respeito do tema privilegia as relações desses coletivos com o Estado e seus antagonistas, nosso foco reside no exame de como as interações entre diferentes tipos de movimentos sociais - incluídos aí aqueles que se organizam em função de princípios diversos aos privilegiados por esses povos e comunidades - desempenham um papel relevante na atribuição de significados concretos à categoria que buscamos examinar. O material empírico de que nos servimos para levar adiante tal discussão inclui eventos ocorridos no Norte de Minas Gerais e em espaços institucionais de participação no âmbito do governo federal.
\end{abstract}

Palavras-chave: Povos e Comunidades Tradicionais. Lutas por Território. Lutas por Terra.

\author{
André Dumans Guedes \\ Doutor em Antropologia Social \\ pela Universidade Federal do Rio \\ de Janeiro - UFRJ. Professor da \\ Univ. Federal Fluminense -UFF. \\ Brasil \\ dumansguedes2@hotmail.com
}

\footnotetext{
Para citar este artigo:

GUEDES, André Dumans. O lugar das interações entre os diferentes movimentos sociais na "definição” dos territórios de povos e comunidades tradicionais . Revista PerCursos, Florianópolis, v. 19, n.39, p. 05 27, jan./abr. 2018.
}

\section{DOI: 10.5965/1984724619392018005}

http://dx.doi.org/10.5965/1984724619392018005 


\title{
The place of interactions among social movements in the "definition" of the territories of traditional peoples and communities
}

\begin{abstract}
Our objective in this paper is to show how the meanings of "territory" as a category have changed in virtue of the struggles of traditional communities and indigenous peoples. In order to do so, we show how important it is to stress the interactions between different social movements (including those organized around principles different than those that define traditional communities), especially because the bibliography concerned with this subject tends to focus on the relations between traditional communities, on one side, and their antagonists and the State, on the order. The empirical material was collected in institutional spaces in Brasília and in northern Minas Gerais.
\end{abstract}

Keywords: Traditional Communities. Struggles for Territory. Struggles for Land. 
O nosso objetivo neste artigo é examinar o modo como alguns sentidos da categoria “território" foram reconfigurados em função da emergência e consolidação das reivindicações, ações coletivas e/ou lutas políticas dos povos e comunidades tradicionais. De modo mais específico, é nosso objetivo destacar o papel desempenhado pelas relações entre diferentes movimentos sociais - seja no que se refere às interações dos participantes de movimentos de povos e comunidades tradicionais entre si ou entre eles e outros movimentos - para o surgimento de tais ressignificações.

Destacamos, desde já, o quão complexa é essa tarefa, e os limites de nossa própria contribuição, ao ressaltar o que há de híbrido ou polissêmico em tal categoria. Começamos, então, lembrando que o "território" é o conceito por excelência da geografia enquanto disciplina'. Colocando a questão em outros termos, poderíamos lembrar que antes (ou além) de ser um conceito acadêmico, o "território" designa uma forma estatal ou paraestatal de governo, evocando uma modalidade historicamente situada de domínio e organização do espaço e da sociedade - tratamos aqui, em suma, de uma espécie de correlato espacial do Estado-nação. Por outro lado, e de modo mais próximo ao assunto discutido aqui, o "território" vem se tornando cada vez mais um conceito ou termo adequado para que certos cientistas sociais possam evocar ou descrever um modo de vida particular - sobretudo quando o que está em jogo são povos, grupos ou comunidades ameaçados ou afetados por frentes ou projetos de desenvolvimento. Temos em mente perspectivas que focam e privilegiam a “espacialização” (e não qualquer espacialização, mas uma que se ancora em certos modelos e pressupostos) destes modos de vida, como se o que houvesse de mais relevante ou essencial neles fosse justamente sua "dimensão territorial”. Um outro sentido do "território" o associa a uma instituição, ou ao produto de uma luta política, ou ao objeto de uma reivindicação perante o Estado. É esse o sentido que está em jogo quando falamos, por exemplo, nos pleitos deste ou daquele povo ou comunidade, diante do Incra ou da Funai, para a demarcação de tal ou qual "território". É, sobretudo, no que concerne à fusão ou imbricação destes últimos dois sentidos - o território como conceito

\footnotetext{
${ }^{1}$ Sem ter como explorar aqui os debates acerca desse conceito capitaneados pelos geógrafos, remeto o leitor à discussão que fiz a esse respeito em Guedes (2016).
} 
para descrever um modo de vida especializado, e o território enquanto instituição ou reivindicação - que desenvolvo meu argumento nesse texto.

O presente artigo se insere, assim, no interior de uma pesquisa coletiva que busca examinar algumas transformações recentes no mundo rural brasileiro, sobretudo no que se refere às formas de organização e construção de sujeitos coletivos e às modalidades de reivindicação de grupos subalternos (ACSELRAD, 2010, 2015). Por um lado, ao longo da última década, presenciamos a proliferação das chamadas "lutas por território", nas quais o que está em jogo é a reivindicação de povos indígenas, quilombolas e comunidades tradicionais pela demarcação coletiva das chamadas "terras tradicionalmente ocupadas". Por outro, tal "guinada territorial” estaria relacionada, via mediações diversas e, na visão de alguns autores, ao enfraquecimento do projeto da reforma agrária clássica, e das "lutas por terra" a ele associado (ALMEIDA, 2007; UMBELINO, 2011).

O que queremos, assim, é não apenas comparar e relacionar tais "lutas por território" às lutas "camponesas" que, desde meados do século XX, têm se centrado na reivindicação de "terras" para o trabalho de unidades familiares; mas também investigar como os sujeitos envolvidos nesses processos têm, eles mesmos, comparado e relacionado essas lutas. Antes de encararmos a "terra" e o "território" como coisas dadas, a cada uma delas se associando natural e automaticamente este ou aquele processo reivindicatório, pretendemos sugerir quão importantes são as práticas que constroem a distinção entre tais entidades para alguns destes sujeitos: no caso considerado neste texto, aqueles envolvidos intelectual e politicamente com as lutas territoriais. Do nosso ponto de vista, tais esforços classificatórios não se direcionam apenas para "consumo externo"; mas são relevantes para estes próprios sujeitos e para a orientação de suas ações. Nesse sentido, podemos desde já assinalar que a distinção em questão deve ser compreendida também como decorrência do próprio processo de constituição das lutas e dos sujeitos nelas envolvidos.

Buscaremos realizar nossos objetivos comparativamente, para tanto examinando como a categoria em questão se faz presente em diferentes contextos e circunstâncias. Consideramos, logo a seguir, alguns eventos ocorridos na Comissão Nacional de Desenvolvimento Sustentável de Povos e Comunidades Tradicionais (CNPTC). Em 
seguida, evocamos alguns episódios - notórios pelo que representaram para a consolidação das lutas aqui consideradas - relativos à emergência dos seringueiros como sujeitos políticos, nos anos 80. Por fim, desviamos nosso olhar para certos embates e debates envolvendo diferentes povos e comunidades tradicionais no norte de Minas Gerais.

\section{O território nas instâncias de participação social}

"Sem o território, ninguém consegue enxergar esses povos", comenta um representante quilombola no encontro regional da Comissão Nacional de Desenvolvimento Sustentável dos Povos e Comunidades Tradicionais (CNPTC) realizado em Belém, em junho de 2014. Na plateia, muitos aquiescem, parecendo sinalizar o quão feliz e relevante foi essa sintética formulação.

O decreto de constituição da CNPTC foi editado em 13/06/2006, tendo tal espaço institucional sido criado, de acordo com seu endereço eletrônico oficial, com a

missão [de] pactuar a atuação conjunta de representantes da Administração Pública direta e membros do setor não governamental pelo fortalecimento social, econômico, cultural e ambiental dos povos e comunidades tradicionais. Entre suas principais atribuições estão coordenar e acompanhar a implementação da Política Nacional de Desenvolvimento Sustentável dos Povos e Comunidades Tradicionais, instituída pelo Decreto $n^{\circ}$ 6.040/07. A CNPCT também propõe princípios e diretrizes para políticas relevantes ao desenvolvimento sustentável dos povos e comunidades tradicionais no âmbito do Governo Federal.

Durante os anos de 2013 e 2014, eu e os pesquisadores Marcelo Moura Mello e José Carlos Matos Pereira realizamos uma série de pesquisas de campo nessa comissão e em outros espaços institucionais em que se prevê a "participação" de representantes de povos e comunidades tradicionais na discussão, elaboração e implementação de políticas 
públicas (GUEDES ET AL, 2014)2. A hipótese que nos norteava então era que as mais relevantes demandas dos povos e comunidades tradicionais presentes em tais espaços diziam respeito a seus “direitos territoriais”. Sem muitas dificuldades ou surpresas, logo nos demos conta de que era de fato nessa direção que se encaminhavam as reivindicações destes sujeitos. O que a pesquisa trouxe de novidade foi a constatação de algumas das consequências dessa centralidade concedida à noção de território sobretudo no que concerne à relação destes diferentes movimentos sociais entre si e junto ao Estado.

No que se refere à relação destes movimentos com o Estado, descobrimos que é justamente a questão do território o elemento-chave para entender a razão de certos grupos - em especial os indígenas - virem se abstendo da participação dos espaços institucionais abordadas por aquela pesquisa. De fato, no período em que realizamos nossa investigação junto ao CNPTC não havia mais quaisquer representantes dos povos indígenas neste fórum. Certo paradoxo permearia assim a construção da questão dos territórios nesses espaços e circunstâncias: ao mesmo tempo que centrais nas reivindicações e na própria constituição (e unificação política) dos povos e comunidades tradicionais, praticamente nenhuma é a capacidade destes grupos "participarem" das políticas públicas que definem a regulação e implementação desses territórios ${ }^{3}$.

Já no que concerne às relações travadas pelos diferentes movimentos entre si, destacamos aqui o modo como certos povos, comunidades e movimentos vêm se apropriando criativamente dessa categoria. Assim, se a vinculação do território às reivindicações indígenas ou quilombolas é aparentemente óbvia, destacamos que o mesmo não ocorre com outros grupos, que apenas mais recentemente vêm se servindo delas. Em Guedes et al. (2014,p.112) mostramos como as lideranças de povos de terreiro

\footnotetext{
${ }^{2}$ Tal investigação se inseria num projeto de pesquisa mais amplo, realizado a partir de uma parceria entre o Fórum de Ciência e Cultura da Universidade Federal do Rio de Janeiro (UFRJ), o Colégio de Altos Estudos dessa mesma instituição (CBAE) e a Secretaria-Geral da Presidência da República, no $1^{\circ}$ mandato da Presidente Dilma Roussef. A investigação foi coordenada pelos professores José Sérgio Leite Lopes e Beatriz Herédia e resultou na publicação de Leite Lopes et al (2014).

${ }^{3}$ Para uma leitura mais aprofundada do que tal contradição expressava a respeito das ambivalências dos projetos políticos dos governos Lula e Dilma, na visão das lideranças desses movimentos de povos e comunidades tradicionais, ver Guedes et al (2014: 106-108).
} 
vêm também realizando investimentos discursivos em torno dessa categoria. No já citado encontro em Belém, essas lideranças

manifestaram inúmeras vezes sua pretensão à criação de seus próprios "territórios", em condições à primeira vista singulares: afinal de contas, eles têm em mente áreas urbanas, e igualmente a realização de práticas extrativas de substâncias (sobretudo vegetais) necessárias a seus rituais [de candomblé ou umbanda]. Particularidades à parte, a presença de elementos como as áreas comuns, a imbricação de um modo de vida singular a um espaço particular, o extrativismo e a preocupação com a preservação ambiental (sobretudo porque os orixás são "a natureza") asseguram que tal "território" seja identificado a "territórios" mais convencionais (como o dos faxinalenses, geraizeiros ou quilombolas).

O território enquanto elemento central às lutas destes movimentos deve assim ser pensado à luz de sua capacidade de, enquanto categoria compartilhada e comum a maior parte dos povos e comunidades tradicionais, abarcar e evidenciar, por outro lado, particularidades e identidades específicas. No evento de Belém, os representantes dos povos de terreiro demonstraram sua consciência de tal capacidade também como estratégia para legitimar e reforçar sua centralidade perante os demais movimentos e comunidades: reivindicando para eles também um território (ou o direito a reivindicá-lo), eles eram capazes de canalizar toda a energia emocional investida em tal termo. Como sugerimos no início dessa seção, nesse evento nada parecia capaz de arrancar mais aplausos do que referências à "defesa dos territórios".

Levando em consideração essas estratégias dos povos de terreiro, podemos afirmar que espaços institucionais como o CNPTC de fato contribuem para aquelas “emulações" através das quais determinado povo, comunidade ou movimento se apropria criativamente de categorias ou práticas de outros grupos. Nesse sentido, vale a pena relacionar esse caso com a rica literatura relativa a como, nos anos 80 , surgiu e consolidou-se o movimento social dos seringueiros (segmento decisivo para o surgimento da própria CNPTC, não custa lembrar).

Cunha e Almeida (2009, p. 283) afirmam que foi o "êxito das reivindicações fundiárias" de certos grupos indígenas na Amazônia o que levou "outros setores 
despossuídos da sociedade, como os quilombolas e [...] os seringueiros [...] a emulá-las". Segundo esses autores, a partir dos anos 80 as "comunidades indígenas, antes desprezadas ou perseguidas pelos vizinhos de fronteira, transformaram-se de repente em modelos". No que se refere aos seringueiros, foi justamente essa "inspiração" fornecida pelos indígenas que Ihes permitiu “inventar” as Reservas Extrativistas (Resex), instituição vinculada ao projeto de "uma reforma agrária que permitisse a continuidade de suas atividades extrativas" (CUNHA; ALMEIDA, 2009, p. 291). O que há de propriamente "criativo" nesta forma particular pode ser explicitado se lembrarmos que, naquele momento e, dado o aparato político e institucional existente, as formas de atuação do Estado que podiam então ser associadas à ideia de "reforma agrária" na Amazônia centravam-se em projetos de colonização, no assentamento em lotes familiares ou na ocupação das margens das rodovias (ALLEGRETTI, 2002; SCHWEICKARDT, 2010). Tais iniciativas previam o envolvimento de colonos vindos de outros lugares do país e não daqueles grupos que, como os seringueiros, já se encontravam lá. O surgimento da proposta de uma "reforma agrária autenticamente amazônica" (SCHWEICKARDT, 2010, p. 129) por parte dos seringueiros, nos parece relevante no contexto da discussão mais ampla deste artigo, por assinalar um momento-chave para se pensar, no Brasil, as distinções entre lutas por “terra” e lutas por “território”. Isso se deu pela criação de uma nova instituição: as Reservas Extrativistas.

Não por acaso, via outros processos de "emulação", essas reservas oferecem nos dias de hoje um dos poucos modelos fundiários disponíveis para a regulamentação de comunidades tradicionais não indígenas ou não quilombolas. Elas assinalam igualmente uma inflexão “identitária” em um tipo de reivindicação - a reforma agrária - usualmente associada a demandas “universalistas". E já nos anos 80, a julgar pelo relato de Cunha e Almeida (2009), fazia-se presente nas demandas seringueiras um daqueles aspectos que, a nosso ver, marcam hoje as demandas por território - seu caráter defensivo. Para estes autores,

quando a palavra "reserva" veio a público em 1985, lida por Chico Mendes na declaração que encerrou o Encontro Nacional de Seringueiros 
realizado em Brasília, ela não tinha um significado preciso. O que ela indicava, conforme a delegação de Rondônia que a introduziu no texto, era que as terras de seringueiros deveriam ter a mesma proteção que as reservas indígenas.

\section{Povos e comunidades tradicionais no norte de Minas Gerais}

Os elementos presentes na discussão da seção anterior nos sugerem então um caminho possível para o exame de algumas das tramas de significação que, nos dias atuais e no contexto dos povos e comunidades que examinamos aqui, articulam-se à ideia de território: tal caminho explora justamente a contraposição dessa categoria à terra.

O Norte de Minas Gerais, que examinamos doravante, oferece condições privilegiadas para tal tipo de análise - e foi também em virtude disso que, em dezembro de 2011, selecionamos tal área para a realização de uma visita de campo e de uma pesquisa empírica. Desde o final do século passado, essa área vem se destacando pela emergência de conflitos socioambientais que opõem diferentes povos e comunidades tradicionais (que, é claro, constituem-se eles próprios no âmbito de tal processo) ao avanço de empreendimentos econômicos de diversas ordens (projetos de reflorestamento, cultivos e agronegócios variados, pastagens, explorações minerais, barragens e usinas hidrelétricas, investimentos em infraestrutura). A luta desses povos e comunidades tradicionais - geraizeiros, vazanteiros, veredeiros, catingueiros, quilombolas e indígenas - foi também objeto de uma bibliografia crescente e de indiscutível qualidade (ver, por exemplo, DAYRELL, 1998; COSTA, 1999; COSTA FILHO, 2008; NOGUEIRA, 2009; BRITO, 2013; SILVEIRA, 2014). É também a existência dessa literatura o que torna possível a análise aqui proposta, que muito deve ao trabalho desses autores.

Mas é preciso lembrar que estes autores são eles próprios sujeitos relevantes nessa luta, o que traz à tona a necessidade de evocarmos esse ponto tão fundamental para quem se propõe ao estudo de movimentos sociais: a questão das relações entre essas lutas e a produção de representações científicas e acadêmicas a respeito delas. Numa primeira aproximação, podemos encarar essa relação à luz daquele "efeito de 
teoria" evocado por Bourdieu (1989), tendo em mente o papel desempenhado pelas descrições científicas na própria constituição das realidades observadas. Por outro lado e na direção oposta, poderíamos estender os comentários de Pacheco de Oliveira (1998, p. 51) a respeito da relação entre questão indígena e a antropologia para outros casos, sugerindo então como segmentos consideráveis das ciências sociais brasileiras "em lugar de definir suas práticas por diálogos teóricos, operam mais com objetos políticos ou ainda com a dimensão política dos conceitos". No que se refere aos povos e comunidades tradicionais, autores diversos (LITTLE, 2002; COSTA FILHO, 2008; NOGUEIRA, 2009; CUNHA e ALMEIDA, 2009) mostraram como o surgimento dessa própria forma de nomeação coletiva se deveu a interações entre esses diferentes sujeitos, com o papel de antropólogos e outros cientistas sociais não podendo ser subestimado aí.

No norte de Minas, pudemos presenciar como a expansão dessa literatura científica se dá pari passu com o desenvolvimento de uma série de relações (políticas, institucionais, pessoais) entre lideranças de movimentos de povos e comunidades tradicionais, professores e alunos universitários, advogados e militantes de outras organizações. Duas instituições devem ser destacadas como espaços privilegiados para a costura dessas alianças: o Centro de Agricultura Alternativa (CAA) e a Universidade Estadual de Montes Claros (Unimontes), sobretudo em espaços associados ao curso de bacharelado em Ciências Sociais e ao Programa de Pós-Graduação em Desenvolvimento Social.

Mas há ainda um fator adicional tornando essa área particularmente interessante para nossos objetivos. Em um primeiro momento de enfrentamento com as mineradoras e o agronegócio, os movimentos sociais então se estruturando aí - e ainda não necessariamente articulados a partir das categorias identitárias que hoje os definem ("geraizeiros" ou "vazanteiros", e.g.) - articularam-se numa aliança com militantes do Movimento dos Trabalhadores Rurais Sem Terra (MST). Como mostram Monção (2009) e Moreira (2010), a presença desse último movimento na região deve ser contextualizada por uma já longa tradição de luta pela terra na região, remontando ao menos ao chamado “Conflito Agrário de Cachoeirinha”, nos anos 1960 e 1970. 
O objetivo norteando a análise do material empírico apresentado na seção seguinte é, então, a descrição de certas “matrizes argumentativas” orientando o modo como aqueles engajados na luta dos povos e comunidades tradicionais de Minas Gerais definem - comparativa e relacionalmente - o que entendem por "território". Tais matrizes aproximam-se daquelas "gramáticas" e "regimes de justificação" evocados por Boltanski e Thévenot (1991). Buscamos assim, em nossas análises, privilegiar o processo de constituição dos grupos sociais a partir de controvérsias e disputas nas quais estão, em primeiro plano, as capacidades e performances reflexivas, cognitivas, classificatórias e/ou críticas dos sujeitos em questão. Como já destacado, o contexto privilegiado para essa análise é aquele em que militantes, intelectuais e lideranças envolvidos nessas "lutas pelo território" nessa região têm construído, para si próprios e para os outros (incluídos aí eu mesmo e os bolsistas que me acompanharam nesse trabalho de campo), a distinção entre “suas" lutas e as lutas de movimentos focados na reforma agrária ou na terra - como é o caso MST.

O material de que nos servimos são falas registradas em entrevistas, gravações autorizadas de reuniões e eventos públicos ou simplesmente anotadas no caderno de campo. Dados os nossos interesses e o limite de espaço para a discussão, desconsideramos aqui quem entre nossos interlocutores as proferiu, bem como o contexto em que isso foi feito. Nosso foco reside, assim, não tanto nas possibilidades e usos táticos e expressivos da argumentação, e mais no elenco destes próprios argumentos e das categorias e oposições que os estruturam ${ }^{4}$. Todas as passagens em negrito correspondem a transcrições literais de falas dos sujeitos em questão.

\section{Análise do material empírico referente ao Norte de Minas Gerais}

No que se refere à distinção entre a terra e o território, um primeiro critério evocado por esses sujeitos centra-se nas particularidades geográficas ou regionais do

\footnotetext{
${ }^{4}$ Agradeço a Bruno Neri Bastos e Joanna Muniz, então bolsistas de iniciação científica do Professor Henri Acselrad, pela discussão dos dados colhidos na viagem ao Norte de Minas Gerais, para onde fomos juntos. Foram eles também que transcreveram as entrevistas e gravações que fizemos durante este trabalho de campo.
} 
Norte de Minas, principalmente através de sua comparação com outras regiões próximas (caso do "Noroeste Mineiro") ou com as quais este Norte de Minas está vinculado por intensos fluxos econômicos e sociais (caso do "Triângulo Mineiro"). Essas particularidades ajudariam a explicar por que o Norte de Minas seria uma área mais propícia ou "vocacionada" às lutas territoriais, enquanto naquelas outras regiões os movimentos seriam muito mais centrados na reforma agrária. No Norte de Minas, o movimento pela reforma agrária seria muito tímido, com poucos assentamentos pela extensão da região; o próprio Incra não conceberia o Norte de Minas como lugar de assentamento.

O Norte de Minas aparece assim como região de fronteira, com uma quantidade significativa de mata nativa; essa sua posição dentro de Minas Gerais interessante contrapondo-se ao que se passara naquelas outras áreas, onde o avanço da ocupação agrícola sobre os espaços naturais é mais intenso e antigo. Não por acaso, entre aqueles já citados vínculos entre o Norte de Minas e o Triângulo Mineiro, destaca-se a migração sazonal de moradores da zona rural da primeira área rumo às grandes plantações existentes na segunda. O contraponto entre os distintos graus de desenvolvimento econômico entre essas áreas é reforçado pelas sugestões de que o Norte de Minas é uma região menos desenvolvida: essa é mesmo uma região que chegou a fazer parte da Sudene. Via esse argumento, reforça-se também o caráter positivamente marcado da singularidade dessa região dentro do estado que a inclui. Norte de Minas, região de fronteira: este último termo sugere então o atraso relativo da chegada do “desenvolvimento" aí; como decorrência disso, os efeitos homogeneizantes induzidos por este último não se fizeram sentir com tanto vigor, o que ajuda a explicar, comparativamente, a permanência nessa área, até hoje, de territorialidades específicas e identidades que já não se fazem tão presentes em outros locais. Disso decorre também a existência de tantos povos e comunidades tradicionais aí.

Mas o argumento de que cada lugar, cada conflito, tem suas diferenças, as suas especificidades, não é utilizado apenas nessa comparação inter-regional - ou seja, naquela em que o Norte de Minas é contraposto ao Triângulo ou Noroeste mineiro. Mesmo que com menor frequência, esse argumento pode ser utilizado no interior da própria região 
que consideramos, ajudando nossos interlocutores a explicar por que, nos limites deste mesmo Norte de Minas, existem sim alguns assentamentos e focos de luta pela terra.

Em segundo lugar, para os sujeitos que nos interessam aqui a oposição entre as lutas por terra e as lutas por território se vinculam à natureza jurídica dos espaços reivindicados em cada uma delas. Criado um assentamento para reforma agrária por parte do Incra, ele será constituído por lotes individuais, para famílias individuais. Já no que diz respeito aos territórios tradicionais, o que está em jogo é a demarcação de uma área coletiva (reserva extrativista, terra indígena, território quilombola, assentamento agroextrativista), sob a responsabilidade de uma comunidade. A intenção não era pegar o meu pedaço, era defender o território, retomar o território. Ou então: tanto que lá não fez, não fez nada de uso coletivo, o povo fatiou tudo também, fatiou tudo, e aqui foi diferente demais. A primeira implicação significativa desta distinção para estes sujeitos reside no argumento de que lotes individuais podem ser vendidos; territórios coletivos não.

Naquele caso que pudemos acompanhar com mais atenção, o dos geraizeiros de Rio Pardo de Minas, a reivindicação reside sobre as áreas de chapada adjacentes aos lotes de propriedade individual, tendo em vista não só mitigar o encurralamento destes últimos, ocasionado por plantações de eucalipto, como também desenvolver usos coletivos tradicionais nesses espaços - como a cria solta do gado ou o extrativismo (cf. Dayrell, 1998; Nogueira, 2009). Opa, então nosso território vai muito além. Não é só meu quintalzinho aqui não, mas o território, e não o pedacinho de dois hectares, três hectares. A gente está pensando é grande.

Note-se que esta oposição entre individual e coletivo, referente à natureza jurídica dos espaços reivindicados (assentamentos com lotes individuais ou território tradicionalmente demarcado) se imbrica e se (con)funde com os sentidos associados a outra atualização particular da oposição entre individual e coletivo: aquela, comum nos movimentos sociais, em que o "egoísmo" ou "individualismo" vinculados ao primeiro polo se contrapõem ao "social” inerente a lutas que são, por definição, coletivas. Pensar o coletivo, o nosso, o território. Se esse deslizamento semântico se verifica em acusações dirigidas dos movimentos "territoriais" para os movimentos pela "terra", ela se verifica também no interior destes últimos: um militante do MST, deslocado para este mesmo 
Norte de Minas para trabalhar junto aos movimentos de luta pela terra, destacava que um dos atrativos das lutas "territoriais" reside no fato delas oferecerem menos espaço para as problemáticas posturas "individualistas" tão comuns em assentamentos da reforma agrária. Para uns e para outros, esse viés "coletivo" do território implica assim num próprio fortalecimento da luta "coletiva”. - Pensar no território. - Não pode pensar em eu, é pensar em nós. - Na comunidade. Uma comunidade, ela existe no território.

Uma terceira diferença entre a "terra" e o "território" está associada às diferentes práticas e habilidades envolvidas nos enfrentamentos contra as empresas e agências do Estado. Como afirmamos acima, em seus primeiros anos, a luta dos povos e comunidades tradicionais contra as mineradoras e o agronegócio no Norte de Minas Gerais foi realizada através de uma aliança das pessoas e organizações tratadas aqui com militantes do Movimento dos Trabalhadores Rurais Sem Terra (MST). A importância desta aliança para o aprendizado de certos procedimentos relativos à luta, bem como para a obtenção de determinadas conquistas, é evidenciada pelas expressões de gratidão manifestas a esse movimento, frequentes entre aqueles envolvidos com as lutas por território no Norte de Minas. Por outro lado, essa mesma aliança se presta para a constituição, reflexão e enunciação de diferenças existentes nas formas de luta. Nesse sentido, os esforços dos sujeitos aqui examinados para singularizar suas lutas deve ser, também, contextualizado por essa aliança ocorrida num passado não tão distante.

Numa primeira aproximação, as distinções enunciadas entre a luta do MST e a luta pelos territórios diz respeito às estratégias e modalidades de mobilização. É assim que o MST é conhecido, por ter mais competência para trabalhar no enfrentamento, [na] questão da ocupação mesmo, para ir para o embate. Foi o que ocorreu nos famosos embates no município de Rio Pardo de Minas, onde conflitos surgiram em função da concessão de terras públicas para empresas reflorestadoras de eucalipto, a partir dos anos 70 (cf. Nogueira, 2009). No momento em que o prazo dessas concessões expirou, os moradores da região - posteriormente identificando-se como "geraizeiros" - buscaram reivindicá-las, também em função da importância delas para formas de uso coletivo “tradicionais" desses moradores. Para tanto, surgiu a ideia de ocupar essas terras, para pressionar o Estado a não renovar essas concessões. Na prática, porém, esses moradores 
não sabiam como promover essas ocupações. Nós já vínhamos discutindo, conversando, parando carruera, empatando serviço, mas não dava resultado. Aí dissemos: "vamos chamar quem sabe fazer". Como organizar os manifestantes, como ocupar uma área: a habilidade e o know-how relativos a essas práticas são atribuídos não apenas ao MST, mas a outras organizações que, histórica e tradicionalmente, estão próximas dos camponeses e da questão da reforma agrária: caso da Comissão Pastoral da Terra, por exemplo.

Do ponto de vista das pessoas envolvidas com essas lutas por território, tais práticas remetem a uma etapa necessária de suas próprias lutas. Porém, vencida essa etapa, com os contratos de concessão às reflorestadoras não sendo renovados, as divergências e diferenças entre os movimentos vieram à tona. Pois, se os militantes do MST defendiam a permanência na área ocupada e a constituição aí de acampamentos estáveis, os que estavam ali no território tinham que continuar produzindo. Não podiam largar a produção, a atividade de produzir, para ir ocupar e ficar debaixo de um barraco de lona. O que está em jogo aí não é apenas a definição de como levar adiante a reivindicação fundiária junto ao Estado; são também diferentes critérios a respeito de quem faz parte da luta. Para o MST, é somente quem faz enfrentamento direto, permanecendo nos acampamentos. Para o pessoal das comunidades, também quem ficou na comunidade faz parte da luta, na medida em que está garantindo as condições para as pessoas estarem lá no acampamento. Segundo nossos interlocutores, foi, sobretudo, em virtude desta divergência que foi rompida aquela aliança. Aí o pessoal do MST ficou puto da vida, falou que nós estávamos querendo mudar o modelo de atuação do MST, que tem vinte anos de atuação.

No exame retrospectivo deste rompimento, aos diferentes sujeitos são atribuídas disposições distintas: num primeiro momento, estas eram complementares, tendo sido necessário juntar um pouco da ousadia dos militantes do movimento com a disposição de defender a casa do geraizeiro. Nesse sentido, alguns dos sujeitos aqui considerados lembravam-se de modo jocoso das acusações direcionadas a eles por estes militantes do MST: pessoas como esses sujeitos, ao contrário dos militantes do MST, não entravam na frente de luta. Na mesma direção vão comentários como o de que os tradicionais tem muito brio, mas não tem essa maneira de fazer enfrentamento -, essa última remetendo 
às agruras ainda mais "radicais" dos sem-terra que encaram sem receios enfrentamentos violentos com a polícia ou o precário cotidiano dos acampamentos. O respeito com que se fala até hoje do MST entre nossos interlocutores evoca assim o próprio respeito que os militantes desse movimento conseguiam impor na região, inclusive diante de políticos, fazendeiros e empresários. Circulando por certo tempo junto a esse sem-terra - esse pessoal perigoso - os militantes e lideranças das lutas territoriais parecem ter sido capazes de aproveitar o embalo e se apropriar de parte desse "capital moral” identificado aos sem-terra. Eles passaram também, com o tempo, a ser temidos e respeitados por alguns políticos, fazendeiros e empresários.

Por outro lado, na comparação com a ousadia dos militantes do MST, a capacidade de defender a casa seria um atributo diferencial e positivo dos "norte-mineiros". Esse mesmo movimento comparativo se articula à identificação dos militantes do MST como forasteiros, pessoas de fora: pessoas que vão embora, ao contrário da comunidade, que fica. Vieram, fez aquele povo, ganhou o lugar, e foi embora, deixou o povo. Ao mesmo tempo, se os povos e comunidades da região são apresentados como população tradicional, é também porque são diferenciados do sem-terra clássico num atributo decisivo: os primeiros são essas mesmas famílias que estão morando aqui - é um povo tradicional, gente que sempre esteve nessa região. Daí também a tensão acima citada, relativa à permanência ou não no acampamento: ao contrário do sem-terra clássico, que não tem terra, as pessoas em questão, do ponto de vista de nossos interlocutores, têm sim seu pequeno lote para cuidar: o que é reivindicado por eles, como visto acima, são as áreas coletivas anexas a esses lotes, as áreas das terras soltas ou gerais (e que correspondem àqueles espaços antes sob a concessão das reflorestadoras de eucalipto).

Mas, se a participação dos sem-terra remete a um momento no processo de luta, uma etapa "camponesa" do processo de reivindicação territorial se faz presente também num contexto ou escala temporal ampliada, referindo-se a lutas que começaram pela reforma agrária, mas se transformaram. Neste último caso, foi somente no transcorrer da própria luta, ou passados anos e mesmo décadas do seu começo, que se fez presente uma inflexão ou guinada territorial ou identitária: é assim que a luta relativamente recente dos quilombolas de Brejo do Crioulo tem sua origem no conflito agrário de 
Cachoeirinha, iniciado nos anos 60 (COSTA, 1999); ou que a mobilização dos gorutubanos tenha como etapa fundamental de sua história o surgimento do assentamento Califórnia (COSTA FILHO, 2008).

Ainda a esse respeito, em certos momentos, as diferentes formas de enfrentamento são pensadas a partir da natureza do antagonista privilegiado: insiste-se, assim no fato de que, ao contrário do que se passa com os sem-terra, cujo adversário é,sobretudo, o latifúndio ( MOREIRA, 2010), no caso das comunidades tradicionais, o embate se dá com empresas modernas - o agronegócio ou a mineração (BRITO, 2013).

Contudo, as divergências entre estas duas modalidades de reivindicação se manifestam não apenas no que se refere aos processos mobilizatórios, pois elas se materializam também nos próprios pressupostos e projetos políticos que as norteiam, já que do ponto de vista dos nossos interlocutores, a compreensão da ideia de identidade, e sua conexão com territorialidades específicas, entra em choque com esse tratamento homogeneizador da agricultura familiar característico do modelão do MST. Esse último movimento, assim como outras organizações ligadas à Via Campesina, teriam suas práticas políticas pautadas pelo princípio de que é preciso colocar todo mundo na mesma fôrma. As experiências diferentes, as diferentes relações com o lugar - que singularizariam, por exemplo, os geraizeiros diante dos caatingueiros, ou estes e aqueles diante dos vazanteiros - não seriam contempladas por este modelão, que prevê tudo igual para todos os grupos, tamanho de terra igual para todo mundo: todos sendo nivelados como sem-terra.

Pela referência a esse modelão são explicitadas também acusações à resistência do MST em reconhecer e aceitar outras modalidades de luta, experiências e tradições. Toda a trajetória histórica prévia e particular desta comunidade, o trabalho político ou comunitário acumulado naquela área específica, seriam desconsiderados ou desvalorizados pelo MST. Este movimento enxergaria nessas singularidades um empecilho ao que deveria ser o modelo correto, único e universal de trabalho mobilizatório: aquele defendido e ensinado por ele próprio. Eles desconsideram o trabalho existente, e querem começar do zero, sempre falando no que falta, na falta, na falta... 
Uma última distinção explicitada entre os movimentos remete à capacidade das lutas territoriais estimularem a invenção de formas inovadoras e usos diferenciados dos recursos à sua disposição. Outro tipo de luta, para demonstrar para a sociedade que outro projeto de uso e ocupação da chapada é possível: seja no que se refere à plantação de arroz, algo que nunca foi experimentado antes; ou para uma produção diferenciada que leve à comercialização de madeira de maneira sustentável. Nestes novos projetos, a “terra” deixa de usufruir da centralidade que usufruía antes, com outras questões se articulando às preocupações propriamente produtivas, e indo além delas. É assim que a retomada da chapada, com a eliminação dos eucaliptos que secavam as nascentes visa garantir água e terra. A terra aí mencionada não aparece apenas como um recurso necessário para a produção, mas vinculada a outras preocupações que se adicionam a ela sem implicar no seu prejuízo: que além da gente conseguir sustentabilidade, conseguir inclusão social, conseguir equilíbrio ecológico, a gente tem resultado também no campo da renda. Daí também a necessidade de harmonizar os resultados com os processos através dos quais eles são obtidos. Não é só focar no resultado; mas como é que a gente qualifica o processo e obtém resultados? Porque não dá você ter resultado e negligenciar o processo. Não ser agroecológico e não ser participativo também não dá certo. Mas não ter resultado no final das contas, você matou a comunidade (DAYRELL, 1998).

Nesta chave argumentativa, ganham um sentido todo particular os argumentos de que o assentamento tem o mesmo modelo das grandes fazendas do agronegócio. Plantação de monocultura, maiores plantadores de feijão em assentamento... E agora mais grave, ele estão com eucalipto. Tem assentamento que o lote inteiro é eucalipto. Em contraposição a esse alegado viés "monocultural” dos assentamentos - a monocultura produtiva eventualmente evocando a monocultura "identitária” destes últimos - os novos modelos "territoriais" em gestão se caracterizariam por uma diversidade tal qual aquela existente, por exemplo, nos assentamentos agroextrativistas: neste caso, e conforme a sugestão de seu próprio nome, a produção agrícola familiar (e/ou comunitária) estaria conjugada ao uso comum de certas áreas destinadas à pecuária ou ao extrativismo. Essa própria diversidade explicitaria também porque, em termos 
ecológicos, o território tradicional dos povos e comunidades tradicionais seria mais sustentável que os assentamentos convencionais dos sem-terra.

\section{Conclusão}

Tentemos sintetizar o que foi discutido na seção anterior, elencando quais seriam os diferentes registros ou matrizes argumentativas em que a diferença entre "terra" e “território" se coloca para os sujeitos que, no Norte de Minas Gerais, estão envolvidos com a causa dos povos e comunidades tradicionais. Tal oposição pode se associar assim: a) a diferenças históricas, geográficas, econômicas e culturais entre certas áreas ou regiões; b) à distinção entre diferentes regimes jurídico-fundiários; c) a diferentes habilidades, estratégias e formas de enfrentamento nos confrontos com os antagonistas destes grupos; d) à natureza da avaliação política das diferenças e singularidades (são elas valores em si ou devem submeter-se a modelos mais gerais e genéricos?); e e) a distintos modos de produzir e utilizar a terra.

Gostaríamos de ressaltar que tais oposições e distinções têm também um valor cognitivo, uma vez que fornecem parâmetros para que, comparativamente, os movimentos de povos e comunidades tradicionais pensem a si próprios. Esse "pensar" tem claramente uma dimensão política, na medida em que se materializa em performances, valores e projetos constituintes da própria identidade desses grupos. Ao confrontarmos o que se passa nesse Norte de Minas àquelas outras situações apresentadas no início do artigo, na CNPTC ou na história dos seringueiros, fica ainda mais evidente o quão relevante foi, para essa constituição cognitiva e política desses coletivos, as interações com outros movimentos sociais. Tais interações se atualizam de modos variados, como vimos: através de alianças e rivalidades; via emulações ou transmissão de habilidades e conhecimentos referentes ao fazer da luta.

Longe de remeter a uma situação excepcional, aquela aliança temporária ocorrida no Norte de Minas Gerais entre sem-terra, de um lado, e povos e comunidades tradicionais, de outro, ajuda-nos a perceber também como, na prática e a priori, as fronteiras entre estas lutas não estão inteira ou prontamente definidas. Se elas existem e 
vêm se consolidando, é também porque são o objeto de um contínuo trabalho político e intelectual. Nossa qualificação desse trabalho como "contínuo" não se justifica apenas em função da emergência relativamente recente das lutas por território ou dos movimentos sociais de povos e comunidades tradicionais. Mas também por acreditarmos ser relevante pensar sociologicamente os movimentos sociais à luz do seu "fazer-se" (THOMPSON, 1987, p. 9). Pensar esses coletivos à luz da perenidade de sua formação eles estando sempre "in the making" (para usar a expressão dificilmente traduzível de E. P. Thompson) - interessa também porque assim podemos perceber melhor a complexa dialética entre continuidades e rupturas que os constituem historicamente. Por um lado, a emergência de novas identidades dos povos e comunidades tradicionais no Norte de Minas estabelece distinções e fronteiras - sobretudo perante as lutas por "terra" ou os movimentos "camponeses" ou de "trabalhadores rurais". Por outro, essa própria necessidade de reforçar continuamente tais distinções e fronteiras, e de fazê-lo de diferentes formas e em contextos variados, tudo isso sugere indiretamente a existência de continuidades de mais longa duração nas lutas populares. De fato, como nossos interlocutores do Norte de Minas frisavam constantemente, a história das lutas contra as reflorestadoras de eucalipto remonta aos anos 70, da mesma forma que a resistência de gorutubanos e quilombolas tem suas raízes em conflitos agrários ainda mais antigos.

É nesse sentido também que justificamos a relevância de nosso foco neste artigo. Se a literatura especializada tende a priorizar as relações que movimentos sociais estabelecem com o Estado e seus antagonistas, aqui chamamos a atenção para a importância de pensá-los à luz de suas interações com outros movimentos sociais.

\section{Referências}

ACSELRAD, Henri. Mapeamentos, Identidades e Territórios. In: ACSELRAD, Henri (Org.) Cartografia social e dinâmicas territoriais: marcos para o debate. Rio de Janeiro: Universidade Federal do Rio de Janeiro, IPPUR, 2010.

ACSELRAD, Henri (Org.). Cartografias sociais, terra e território. Rio de Janeiro: Universidade Federal do Rio de Janeiro: IPPUR, 2015. 
ALEGRETTI, Mary. A Construção social de políticas ambientais: Chico Mendes e o movimento dos seringueiros. 2002. Tese (Doutorado em Desenvolvimento Sustentável) UnB, Centro de Desenvolvimento Sustentável, Brasília, 2002.

ALMEIDA, Mauro. Narrativas agrárias e a morte do campesinato. Ruris, v.1, n.2, setembro 2007.

BOLTANSKI, LUC; THÉVENOT, Laurent. De la justification: les économies de la grandeur. Paris: Éditions Gallimard, 1991.

BOURDIEU, Pierre. O Poder Simbólico. São Paulo: Difel, 1989.

BRITO, Isabel Cristina Barbosa. Ecologismo dos Gerais: conflitos socioambientais e comunidades tradicionais no Norte de Minas Gerais. 2013. Tese (Doutorado em Desenvolvimento Sustentável) - UnB, Centro de Desenvolvimento Sustentável, Brasília, 2013.

CUNHA, Manuela Carneiro da; ALMEIDA, Mauro.Populações tradicionais e conservação ambiental. In: CUNHA, Manuela Carneiro da, Cultura com aspas. São Paulo: Cosac Naify.

COSTA, João Batista de Almeida. Do Tempo da Fartura dos Crioulos ao Tempo de Penúria dos Morenos: a Identidade através de um Rito em Brejo dos Crioulos (MG). 1999. Dissertação (Mestrado em Antropologia Social) - UnB,, PPGAS/DAN, Brasília, 1999.

CUNHA, Manuela Carneiro da; ALMEIDA, Mauro. Populações tradicionais e conservação ambiental. In: CUNHA, Manuela Carneiro da Cultura com Aspas. São Paulo: Cosac Naif, 2009 .

DAYRELL, Carlos Alberto. Geraizeiros e biodiversidade no Norte de Minas: a contribuição da agroecologia e da etnoecologia nos estudos dos agrossistemas tradicionais. 1998. Dissertação (Mestrado em Agroecologia) - Universidade Internacional de Andalucia, Programa de Agroecologia y Desarrollo Rural Sostenible, 1998.

COSTA FILHO, Aderval. Os gorutubanos: territorialização, produção e sociabilidade em um quilombo do centro norte-mineiro 2008. Tese (Doutorado em Antropologia Social) UnB - PPGAS/DAN, Brasília, 2008.

GUEDES, André Dumans. 2016. Lutas por terra e território, desterritorialização e o território como forma social. Revista Brasileira de Estudos Urbanos e Regionais (ANPUR), v. 18, p. 23-39, 2016.

GUEDES, André DumanS; PEREIRA, José Carlos Matos; MELLO, Marcelo Moura. Conflitos, Visibilidades e Territórios. A Participação Social da Perspectiva dos Povos e Comunidades 
Tradicionais. In: LEITE LOPES, José Sérgio; HEREDIA, Beatriz. (Org.). Movimentos Sociais e Esfera Pública. O Mundo da Participação: Burocracias, Confrontos, Aprendizados Inesperados. 1ed.Rio de Janeiro: Colégio Brasileiro de Altos Estudos, 2014, v. 1.

LOPES, José Sérgio Leite; HEREDIA, Beatriz (Orgs). Movimentos sociais e esfera pública: o mundo da participação: burocracias, confrontos, aprendizados inesperados. Rio de Janeiro: Colégio Brasileiro de Altos Estudos (CBAE), 2014.

LITTLE, Paul. Territórios sociais e povos tradicionais no Brasil: por uma antropologia da territorialidade. Brasília:, UnB, 2002. (Série Antropologia, n.322).

MONÇÃO, Kátia Maria Gomes. As sementes da luta: o conflito agrário de Cachoeirinha Um estudo dos assentamentos e dos acampamentos do município de Verdelândia, Norte de Minas Gerais. 2009. Dissertação (Mestrado em Desenvolvimento Social) - Unimontes, PPGDS, Montes Claros, 2009.

MOREIRA, Hugo Fonseca. Se for pra morrer de fome, eu prefiro morrer de tiro: o Norte de Minas e a Formação de Lideranças Rurais. 2010. Dissertação (Mestrado em Ciências Sociais em Desenvolvimento, Agricultura e Sociedade) - UFRRJ, CPDA, , 2010.

NOGUEIRA, Mônica Celeida Rabelo. Gerais a dentro e a fora: identidade e terrritorialidade entre geraizeiros do norte de Minas Gerais.2009. Tese (Doutorado em Antropologia Social) - UnB, PPGAS, DAN, , Brasília, 2009.

OLIVEIRA, João Pacheco de. Uma etnologia dos 'índios misturados? Situação colonial, territorialização e fluxos culturais. Mana, v.4, n.1, 1998.

SCHWEICKARDT, Kátia Helena Serafina Cruz. As diferentes faces do Estado na Amazônia: etnografia dos processos de criação e implantação da RESEX Médio Juruá e da RDS Uacari no Médio Rio Juruá. 2010. Tese (Doutorado em Antropologia) - UFRJ, PPGSA, IFCS, Rio de Janeiro, 2010.

SILVEIRA, Dayana Martins.Comunidades tradicionais do Norte de Minas: estratégias de luta e acesso a direitos territoriais, 2014. Dissertação (Mestrado em Desenvolvimento Social) - Unimontes, PPGDS, Montes Claros, 2014.

THOMPSON, Edward Palmer. A formação da classe operária inglesa. Rio de Janeiro: Paz e Terra, 1987.

UMBELINO, Ariosvaldo. Os posseiros voltam a assumir o protagonismo da luta camponesa pela terra no Brasil. In: UMBELINO, Ariosvaldo. Conflitos no Campo no Brasil 2010. Goiânia: Comissão Pastoral da Terra, 2011. 
O lugar das interações entre os diferentes movimentos sociais na "definição" dos territórios de povos e comunidades tradicionais

André Dumans Guedes

\section{Recebido em: 08/12/2017 \\ Aprovado 23/04/2018}

Universidade do Estado de Santa Catarina - UDESC

Centro de Ciências Humanas e da Educação - FAED

Revista PerCursos

Volume 19 - Número 39 - Ano 2018

revistapercursos@gmail.com 